\title{
Effect of thyme and oregano essential oils on the shelf life of salmon and seaweed burgers
}

\author{
Dolea1 ${ }^{1}$, A Rizo $^{2}$, A Fuentes ${ }^{1}$, JM Barat ${ }^{1}$ and \\ I Fernández-Segovia ${ }^{1}$
}

\begin{abstract}
The effect of different essential oils on the quality and shelf life of fish and seaweed burgers during storage was evaluated. For this purpose, thyme and oregano essential oils were selected at a concentration of $0.05 \%$ $(\mathrm{v} / \mathrm{w})$. Three types of salmon and seaweed burgers were prepared: without essential oil, burgers with red thyme essential oil $(0.05 \%(\mathrm{v} / \mathrm{w}))$ and burgers with oregano essential oil $(0.05 \%(\mathrm{v} / \mathrm{w}))$, which were vacuum packaged and stored at $4{ }^{\circ} \mathrm{C}$ for 17 days. Physicochemical and microbiological analyses were carried out periodically throughout storage. The addition of both essential oils did not have any effect on the evolution of the $\mathrm{pH}$, the moisture content or texture parameters. Only the thyme essential oil managed to slightly slow down the increase of total volatile basic nitrogen and trimethylamine nitrogen. The samples with oregano essential oil and especially those with thyme essential oil showed minor oxidation. The salmon and seaweed burgers without essential oils and those which contained oregano essential oil showed a faster increase of mesophilic counts than those which had thyme essential oil, but no noticeable improvement was observed in the shelf life of the burgers with thyme essential oil. To improve the shelf life of the fish and seaweed burgers, it would be necessary to increase the concentration of both essential oils.
\end{abstract}

\section{Keywords}

Algae, antimicrobial agents, antioxidants, essential oils, fish and fish products

Date received: 1 September 2017; accepted: 22 January 2018

\section{INTRODUCTION}

In the last decades, an increase in the use of seaweeds as food ingredients in western countries has been observed. This fact is closely linked to the excellent nutritional composition and functional properties that seaweeds exhibit. They are rich in proteins, essential amino acids and minerals (Peinado et al., 2014; Rupérez, 2002). These marine plants have low fat content which implies the low caloric value that they add. It is important to highlight the significant amount of fibre which seaweeds provide (Cofrades et al., 2008; Gómez-Ordóñez et al., 2010). The phenolic compounds present in the seaweeds are also noticeable, responsible

Food Science and Technology International 24(5) 394-403

(C) The Author(s) 2018 Reprints and permissions:

sagepub.co.uk/journalsPermissions.nav

DOI: $10.1177 / 1082013218759364$

journals.sagepub.com/home/fst

๑SAGE for their antioxidant capacity (Farvin and Jacobsen, 2013). This property is important for human health, because the oxidative processes are involved in a wide variety of diseases. In addition, the lipid oxidation plays an important role in the fatty food spoilage, where the use of synthetic additives is very often necessary. Seaweeds could be an alternative to the use of this type of additives, constituting a natural source of antioxidants.

The bioactive compounds present in seaweeds have also been proven to exhibit antimicrobial action against

\footnotetext{
${ }^{1}$ Departamento de Tecnología de Alimentos, Universitat Politècnica de València, Valencia, Spain

${ }^{2}$ Instituto de Agroquímica y Tecnología de Alimentos (IATA-CSIC), Valencia, Spain

Corresponding author:

I Fernández-Segovia, Departamento de Tecnología de Alimentos, Universitat Politècnica de València, Camino de Vera s/n, Valencia 46022, Spain.

Email: isferse1@tal.upv.es
} 
gram-positive and gram-negative bacteria (Gupta and Abu-Ghannam, 2011). This property would allow seaweeds to replace chemical preservatives.

At present the incorporation of seaweeds as a functional ingredient constitutes an interesting alternative in the development of new healthy food products, which are both natural and have high nutritional value.

In the search for alternatives to the synthetic preservatives or antioxidant, the essential oils (EOs) obtained from plants have also been widely studied. The antimicrobial and antioxidant activity of EOs is due to their high levels of phenolic compounds. In this sense, thyme is characterized by high concentrations of thymol and p-cymene, and to a lesser extent $\alpha$-pinene and linalool. Oregano has high contents of carvacrol and p-cymene, with other compounds, such as thymol, in lower concentrations. Clove is characterized by its high content in eugenol, while cinnamon is rich in cinnamic aldehyde, among others. Rosemary shows important contents of borneol, camphor, $\alpha$-pinene and 1,8-cineol (Ballester-Costa et al., 2013; Perricone et al., 2015; Pesavento et al., 2015). The effectivity in the inhibition of microbial growth and the antioxidant capacity of some EOs, such as rosemary, oregano, thyme or cinnamon, on fish and meat products have been proven in several studies (Abdollahzadeh et al., 2014; Kostaki et al., 2009; Kykkidou et al., 2009; Mexis et al., 2009; Pesavento et al., 2015).

The aim of this work was to evaluate the effect of different EOs on the quality and shelf life of salmon and seaweed burgers during storage.

\section{MATERIALS AND METHODS Materials}

Fish. Aquacultured salmon (Salmo salar) of commercial size (weighing 2-3 kg) from a Norwegian farm (Hallvard Leroy, Bergen, Norway) was used as raw material. The fish were purchased in a local supermarket in Valencia (Spain). The specimens were headed, gutted and filleted, and two fillets were obtained from each fish. On arrival at the laboratory, the fillets were frozen at $-20^{\circ} \mathrm{C}$ until processing and analysis, for a total period of $72 \mathrm{~h}$.

Seaweed. Dehydrated and powdered seaweeds were used as raw material. Four types of seaweeds (kombu (Laminaria ochroleuca), wakame (Undaria pinnatifida), espagueti de mar (Himanthalia elongata) and agar-agar (Gelidium sesquipedale)) were provided by the company Porto-Muiños (Cerceda, A Coruña, Spain).

EOs. Three EOs were studied: red thyme EO (Thymus zygis L.), cinnamon bark EO (Cinnamomum zeylanicum) and oregano EO (Origanum vulgare L.). They were provided by the company Ernesto Ventós, S.A. (Sant Just Desvern, Barcelona, Spain). According to the manufacturer's specifications, red thyme EO was obtained from the entire flowering plant (without root), the cinnamon bark EO was obtained from the dried bark and had a content of cinnamic aldehyde $>60 \%$ and safrole $<0.1 \%$, and the oregano EO was obtained from the flowering tops and the phenol contents ranged from 60 to $75 \%$.

\section{Selection of EO concentrations}

A preliminary sensory study was conducted to select the concentration of each EO which was sensorially acceptable. The concentrations of red thyme, cinnamon bark and oregano EOs are shown in Table 1. To select the concentration of each EO to be added to the burgers for the final study, seven trained panellists were used (two men and five women), members of the Food Technology Department at the Universitat Politècnica de València, which had participated in previous studies of development of burgers, pâtes and sausages made of seaweeds and fish.

Burger samples were presented to the panel in two different sessions. In the first one, nine samples were evaluated (the three EOs at $0.5,0.25$ or $0.10 \% \mathrm{v} / \mathrm{w}$ ). In the second one, six samples were tested (the three EOs at 0.05 or $0.025 \% \mathrm{v} / \mathrm{w}$ ) (Table 1). The panellists had to decide by consensus if each of the samples evaluated was sensorially acceptable or not. Based on the results obtained in this preliminary study, as will be explained in the 'Results and Discussion' section, two EOs were selected (red thyme and oregano) at the concentration of $0.050 \mathrm{ml} / 100 \mathrm{~g}$ sample. Sample preparation was conducted following the procedure described below.

\section{Sample preparation}

Salmon fillets were thawed during $24 \mathrm{~h}$ at $4{ }^{\circ} \mathrm{C}$. Salmon skin and remaining bones were removed and it was cut into pieces of $3 \mathrm{~cm} \times 3 \mathrm{~cm}$ approximately. The portions were randomly divided into three batches. Batch 1 was used to prepare control samples (Ct samples), which consisted of burgers made of salmon and seaweeds

Table 1. Essential oil (EO) concentrations used in the preliminary study

\begin{tabular}{llrrrr}
\hline EO & \multicolumn{4}{l}{ Concentration } & (ml EO/100 g sample) \\
\hline Red thyme & 0.50 & 0.25 & 0.10 & 0.050 & 0.025 \\
Cinnamon bark & 0.50 & 0.25 & 0.10 & 0.050 & 0.025 \\
Oregano & 0.50 & 0.25 & 0.10 & 0.050 & 0.025 \\
& First session & & \multicolumn{3}{c}{ Second session } \\
\hline
\end{tabular}


without EOs. Portions in batches 2 and 3 were used to prepare salmon-seaweeds burgers with red thyme EO $(0.050 \mathrm{ml} / 100 \mathrm{~g}$ sample) (T samples) and with oregano EO (Og samples) $(0.050 \mathrm{ml} / 100 \mathrm{~g}$ sample), respectively (Figure 1).

Portions of each batch were weighed and minced in the Thermomix ${ }^{\circledR} \quad($ Vorwerk \& Co., Wuppertal, Germany) for $45 \mathrm{~s}$. Then, a mixture of the four seaweeds in powder were added in the necessary amount up to a final content of $1 \%$ kombu, $1 \%$ wakame, $3 \%$ sea spaghetti and $1 \%$ agar-agar $(\mathrm{w} / \mathrm{w})$, and the fish with the seaweeds were homogenized for $45 \mathrm{~s}$ in the Thermomix ${ }^{\circledR}$, until obtaining an homogeneous paste (sample $\mathrm{Ct}$ ). This methodology was based on previous studies carried out by the authors (data not published).

Burgers with EOs were prepared in the same way as control samples, incorporating the EO at the same time as the seaweed mixture (Figure 1).

Finally, the paste obtained was divided into $30 \mathrm{~g}$ portions, which were introduced into a mould to give the typical shape of small burgers. All samples were vacuum packaged (two burgers/bag) using high barrier bags and stored at $4{ }^{\circ} \mathrm{C}$ for 17 days.

\section{Analytical determinations}

Physicochemical and microbiological analyses of the burgers were performed on days $0,3,7,10,14$ and 17 of refrigerated storage. Three bags of each batch were randomly taken on each sampling day $(n=3)$. The analyses were performed in duplicate on each sample.

\section{Physicochemical analyses}

Moisture contents were determined according to the AOAC method 950.46 (1997).

A pH meter (Crison Instruments, S.A., Barcelona, Spain) was used to measure $\mathrm{pH}$ values, previously homogenizing the samples in distilled water (weight:volume ratio 1:10).

The total volatile basic nitrogen (TVB-N) and trimethylamine nitrogen (TMA-N) contents were determined by steam distillation according to the method described by Malle and Tao (1987). Thirty grams of sample was weighed and homogenized with $60 \mathrm{ml}$ of trichloroacetic acid solution $7.5 \%(\mathrm{w} / \mathrm{v})$, centrifuged at $3000 \mathrm{rpm} / \mathrm{min}$ for $5 \mathrm{~min}$. The supernatant was filtered through a Whatman No. 1 filter, obtaining the extract

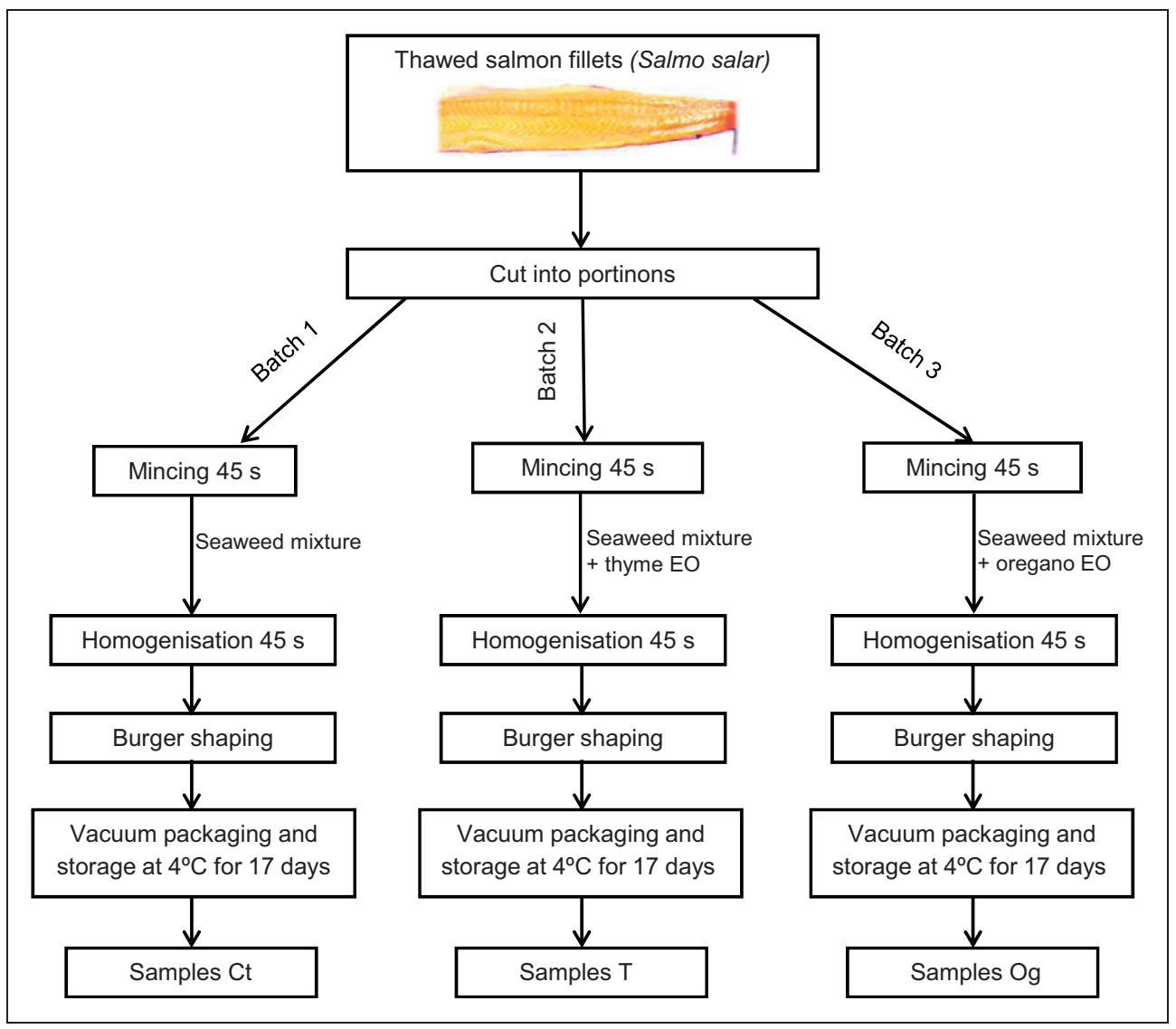

Figure 1. Flow diagram of sample preparation. 
of the sample. For TVB-N determination, $5 \mathrm{ml}$ of $\mathrm{NaOH} 10 \%(\mathrm{w} / \mathrm{v})$ was added to $25 \mathrm{ml}$ of the extract and it was submitted to steam distillation in a Unit Pro Nitro M, SELECTA (Barcelona, Spain). The ammonia was collected in $15 \mathrm{ml}$ of boric acid at $4 \%$ $(\mathrm{w} / \mathrm{v})$ and titrated with sulphuric acid $0.01 \mathrm{~N}$. Results were expressed as $\mathrm{mg} \mathrm{N} / 100 \mathrm{~g}$ sample. The same procedure was followed for TMA-N analysis, except for the addition of $20 \mathrm{ml}$ of formaldehyde solution $35 \%$ $(\mathrm{v} / \mathrm{v})$ to the extract before distillation, in order to block primary and secondary amines.

The thiobarbituric acid (TBA) index was measured using a spectrophotometric method with some minor modifications (Tarladgis et al., 1960) to evaluate oxidation stability during chilled storage. The method is based on the measurement of absorbance at $530 \mathrm{~nm}$ of a chromogen formed by reaction between thiobarbituric acid and malondialdehyde (MDA) (one of the main compounds formed as a result of lipid oxidation).

\section{Texture measurements}

Texture profile analysis (TPA) was performed by use of a Texture Analyser TA.XT2 ${ }^{\circledR}$ (Stable Micro Systems, Surrey, UK), equipped with a load cell of $250 \mathrm{~N}$. Samples were obtained by cutting out pieces of $2 \mathrm{~cm} \times 2 \mathrm{~cm}$ from the central part of each burger. For TPA analysis a flat-ended cylindrical plunger $(7.5 \mathrm{~cm}$ diameter) was used. The plunger was pressed into the sample at a constant speed of $1 \mathrm{~mm} / \mathrm{s}$ until it reached $50 \%$ of the sample height, in order to simulate jaw movement during mastication (Bourne, 1978). Force-distance curves were processed in order to obtain the texture parameters: hardness, cohesiveness, elasticity, chewiness and resilience.

\section{Microbiological analyses}

Mesophilic bacteria and Enterobacteriaceae were determined according to the methods given by the ISO standards 4833:2003 and 21528-2:2004, respectively. All the analyses were performed in duplicate and the results were expressed as $\log \mathrm{cfu} / \mathrm{g}$. All the culture media were provided by Scharlau Chemie, S.A. (Barcelona, Spain).

\section{Statistical analysis}

During the storage study, the data relating to each parameter were analysed with a multifactor ANOVA to evaluate the effect of the EO and of the storage time and their interactions. All the physicochemical and microbiological parameters were considered as dependent variables and type of EO and the storage time were the factors in these analyses. Data are reported as mean \pm standard deviation. Statistical treatment of the data was performed using the Statgraphics Centurion software (Statpoint Technologies, Inc., Warrenton, VA, USA).

\section{RESULTS AND DISCUSSION Selection of EO concentrations}

The EOs have strong odours and flavours, which is why it is necessary to check that the amount incorporated to a food product is acceptable from a sensorial point of view. In the first session of the sensorial analysis, panellists evaluated the three EOs (red thyme, cinnamon bark and oregano) at the highest concentrations $(0.5,0.25$ and $0.1 \mathrm{ml} \mathrm{EO} / 100 \mathrm{~g}$ sample) in the burgers, as mentioned above. They concluded that for those concentrations, the burgers were not acceptable for any of the EOs.

In the second session, the concentrations tested were 0.05 and $0.025 \mathrm{ml} \mathrm{EO} / 100 \mathrm{~g}$ sample, for the three EOs. Panellists established that the cinnamon EO conferred a strong, odd flavour to the burgers, not being acceptable at any of the concentrations used. For the red thyme and oregano EOs for both concentrations, they concluded that, although the burgers had typical flavours of these EOs, they could be acceptable for consumers.

Based on these results, the use of cinnamon EO was rejected for the final study. For the red thyme and oregano EOs, the concentration of $0.05 \mathrm{ml} / 100 \mathrm{~g}$ was chosen, since it was the highest amount at which the burgers obtained may be sensorially acceptable. Nevertheless, this study should be completed with a further sensory analysis to check the consumer's acceptation with hedonic trials using a high number of non-trained panellists.

It is important to note that in other studies carried out on swordfish with thyme EO, contents of $0.1 \%$ $(\mathrm{v} / \mathrm{w})$ in fresh fish were sensorially acceptable. However, in other works on squid rings, concentrations equal to or over $0.075 \%$ of thyme and oregano EOs in the coating mixture, gave a strong odour in the final product, using concentrations equal to or below $0.05 \%$ (Sanjuás-Rei et al., 2012), which agrees with this work.

\section{Quality and shelf life study}

Changes in the physicochemical parameters during storage. Values of $\mathrm{pH}$ and moisture content in the three types of burgers $(\mathrm{Ct}, \mathrm{T}$ and $\mathrm{Og}$ ) during cold storage are shown in Table 2. Initially, $\mathrm{pH}$ was approximately 6.2, with no significant differences between the three types of samples. This parameter slightly decreased from day 0 to day 14 , showing a slight increase from this sampling day onwards, as has been observed in other fish studies (Cai et al., 2015; Mexis et al., 2009).

The initial decrease could be due to the growth of lactic acid bacteria with the subsequent lactic acid formation. The final increase could be due to basic 
Table 2. Evolution of $\mathrm{pH}$, moisture and texture parameters in salmon and seaweed burgers: without essential oils (Ct), with thyme essential oil $(\mathrm{T})$ and with oregano essential oil $(\mathrm{Og})$, during 17 days of storage at $4{ }^{\circ} \mathrm{C}$. (means and standard deviations)

\begin{tabular}{|c|c|c|c|c|}
\hline Parameters & $\begin{array}{l}\text { Days of } \\
\text { storage }\end{array}$ & $\mathrm{Ct}$ & $\mathrm{T}$ & $\mathrm{Og}$ \\
\hline \multirow[t]{6}{*}{$\mathrm{pH}$} & 0 & $6.19 \pm 0.01$ & $6.21 \pm 0.01$ & $6.20 \pm 0.01$ \\
\hline & 3 & $6.14 \pm 0.03$ & $6.24 \pm 0.03$ & $6.22 \pm 0.04$ \\
\hline & 7 & $6.10 \pm 0.00$ & $6.14 \pm 0.04$ & $6.11 \pm 0.01$ \\
\hline & 10 & $6.08 \pm 0.01$ & $6.03 \pm 0.01$ & $6.01 \pm 0.01$ \\
\hline & 14 & $6.02 \pm 0.01$ & $6.03 \pm 0.05$ & $5.99 \pm 0.03$ \\
\hline & 17 & $6.05 \pm 0.03$ & $6.06 \pm 0.00$ & $6.05 \pm 0.02$ \\
\hline \multirow[t]{6}{*}{ Moisture } & 0 & $63.2 \pm 0.4$ & $63.2 \pm 0.9$ & $62.9 \pm 0.3$ \\
\hline & 3 & $62.6 \pm 0.4$ & $63.5 \pm 0.8$ & $62.5 \pm 0.2$ \\
\hline & 7 & $63.1 \pm 0.8$ & $63.4 \pm 0.3$ & $62.9 \pm 0.2$ \\
\hline & 10 & $64.1 \pm 0.5$ & $65.4 \pm 0.7$ & $64.2 \pm 0.1$ \\
\hline & 14 & $65.1 \pm 0.6$ & $65.3 \pm 0.1$ & $64.5 \pm 0.1$ \\
\hline & 17 & $64.1 \pm 0.4$ & $63.9 \pm 0.2$ & $63.4 \pm 0.1$ \\
\hline \multicolumn{5}{|l|}{ Texture } \\
\hline \multirow[t]{6}{*}{ Hardness $(\mathrm{N})$} & 0 & $3.27 \pm 0.01$ & $3.91 \pm 0.01$ & $3.68 \pm 0.01$ \\
\hline & 3 & $7.08 \pm 0.07$ & $4.79 \pm 0.08$ & $4.8 \pm 0.8$ \\
\hline & 7 & $5.1 \pm 0.8$ & $4.2 \pm 0.1$ & $5 \pm 2$ \\
\hline & 10 & $3.76 \pm 0.06$ & $5.6 \pm 0.4$ & $5.2 \pm 0.3$ \\
\hline & 14 & $5 \pm 2$ & $4.7 \pm 0.7$ & $6 \pm 2$ \\
\hline & 17 & $4.5 \pm 0.7$ & $5.1 \pm 0.4$ & $6 \pm 2$ \\
\hline \multirow[t]{6}{*}{ Adhesiveness (gs) } & 0 & $-0.09 \pm 0.00$ & $-0.12 \pm 0.01$ & $-0.07 \pm 0.01$ \\
\hline & 3 & $-0.29 \pm 0.02$ & $-0.19 \pm 0.03$ & $-0.16 \pm 0.06$ \\
\hline & 7 & $-0.13 \pm 0.03$ & $-0.13 \pm 0.03$ & $-0.16 \pm 0.09$ \\
\hline & 10 & $-0.11 \pm 0.01$ & $-0.26 \pm 0.04$ & $-0.18 \pm 0.05$ \\
\hline & 14 & $-0.2 \pm 0.1$ & $-0.15 \pm 0.01$ & $-0.19 \pm 0.06$ \\
\hline & 17 & $0.19 \pm 0.09$ & $-0.29 \pm 0.09$ & $-0.17 \pm 0.08$ \\
\hline \multirow[t]{6}{*}{ Elasticity } & 0 & $0.54 \pm 0.00$ & $0.60 \pm 0.01$ & $0.55 \pm 0.01$ \\
\hline & 3 & $0.70 \pm 0.03$ & $0.64 \pm 0.04$ & $0.63 \pm 0.02$ \\
\hline & 7 & $0.65 \pm 0.03$ & $0.65 \pm 0.03$ & $0.5 \pm 0.2$ \\
\hline & 10 & $0.66 \pm 0.03$ & $0.78 \pm 0.08$ & $0.65 \pm 0.09$ \\
\hline & 14 & $0.76 \pm 0.07$ & $0.70 \pm 0.01$ & $0.6 \pm 0.2$ \\
\hline & 17 & $1.4 \pm 0.1$ & $1.40 \pm 0.09$ & $1.4 \pm 0.6$ \\
\hline \multirow[t]{6}{*}{ Chewiness (N) } & 0 & $0.89 \pm 0.00$ & $1.23 \pm 0.01$ & $0.99 \pm 0.05$ \\
\hline & 3 & $2.6 \pm 0.1$ & $1.6 \pm 0.1$ & $1.6 \pm 0.4$ \\
\hline & 7 & $1.9 \pm 0.2$ & $1.6 \pm 0.1$ & $1.6 \pm 0.9$ \\
\hline & 10 & $1.5 \pm 0.3$ & $2.58 \pm 0.02$ & $1.96 \pm 0.01$ \\
\hline & 14 & $2.8 \pm 0.7$ & $1.9 \pm 0.3$ & $2.3 \pm 0.9$ \\
\hline & 17 & $3.44 \pm 0.04$ & $4.1 \pm 0.7$ & $5 \pm 4$ \\
\hline \multirow[t]{6}{*}{ Cohesiveness } & 0 & $0.50 \pm 0.00$ & $0.52 \pm 0.00$ & $0.49 \pm 0.01$ \\
\hline & 3 & $0.53 \pm 0.01$ & $0.54 \pm 0.01$ & $0.54 \pm 0.01$ \\
\hline & 7 & $0.54 \pm 0.04$ & $0.56 \pm 0.02$ & $0.62 \pm 0.09$ \\
\hline & 10 & $0.54 \pm 0.01$ & $0.59 \pm 0.01$ & $0.57 \pm 0.04$ \\
\hline & 14 & $0.57 \pm 0.03$ & $0.59 \pm 0.01$ & $0.6 \pm 0.1$ \\
\hline & 17 & $0.6 \pm 0.2$ & $0.60 \pm 0.02$ & $0.59 \pm 0.02$ \\
\hline
\end{tabular}


Table 2. Continued

\begin{tabular}{lcccc}
\hline Parameters & $\begin{array}{l}\text { Days of } \\
\text { storage }\end{array}$ & Ct & T & Og \\
\hline Resilience & 0 & $0.15 \pm 0.00$ & $0.15 \pm 0.00$ & $0.15 \pm 0.00$ \\
& 3 & $0.15 \pm 0.00$ & $0.15 \pm 0.00$ & $0.15 \pm 0.00$ \\
7 & $0.15 \pm 0.01$ & $0.17 \pm 0.01$ & $0.24 \pm 0.08$ \\
10 & $0.16 \pm 0.00$ & $0.15 \pm 0.00$ & $0.18 \pm 0.01$ \\
14 & $0.16 \pm 0.00$ & $0.18 \pm 0.00$ & $0.21 \pm 0.07$ \\
17 & $1 \pm 1$ & $0.18 \pm 0.02$ & $0.18 \pm 0.02$ \\
\hline
\end{tabular}

compounds formation as a consequence of fish spoilage. The EOs incorporation did not affect the $\mathrm{pH}$ values throughout the storage, with no significant differences between samples. These results agree with those observed by Kykkidou et al. (2009), where the thyme EO incorporated to fresh fish did not have any effect on the $\mathrm{pH}$ evolution.

Moisture values varied during storage with no clear trend. T samples exhibited values slightly higher than the other two types of burgers, although the statistical analysis showed no statistical differences between samples $(\mathrm{p}>0.05)$.

The TVB-N, TMA-N and TBA index evolution are shown in Figure 2(a) to (c), respectively. The TVB-N is widely used as a fish spoilage index, since an increase in this parameter has been associated with the spoilage specific bacterial growth and with endogenous enzyme activity, which entail the loss of quality in fish (Özyurt et al., 2009). The acceptability limit of TVB-N varies depending on the fish species, season, region, age or sex. This parameter also depends on whether the fish is fresh or processed.

According to Regulation 2074/2005, the European Commission (2005) considers an acceptable value of $35 \mathrm{mg} \mathrm{N} / 100 \mathrm{~g}$ for $S$. salar. In control sample $(\mathrm{Ct})$, the value of this parameter increased from 18.9 up to $32 \mathrm{mg}$ $\mathrm{N} / 100 \mathrm{~g}$ at day 10 of storage. The acceptability limit was exceeded on day 14 , showing an important increase through to day 17 of study, where values were significantly higher than those with EOs. Burgers with oregano EO showed a similar pattern to the $\mathrm{Ct}$ samples. In samples with thyme EO, the TVB-N levels kept under the acceptability limit until day 17 , although at day 14, $\mathrm{T}$ samples exhibited values very close to $\mathrm{Ct}$ and $\mathrm{Og}$ samples. From these results, it can be concluded that the EOs only showed a slight effect at the end of the studied period, but they would not be able to inhibit or delay spoilage, from the point of view of this parameter, since values close to the acceptability limits were obtained practically at the same time for the three types of samples.

Initial values of TMA-N range from 3 to $4 \mathrm{mg}$ $\mathrm{N} / 100 \mathrm{~g}$ of sample. In Figure 2(b) a progressive increase

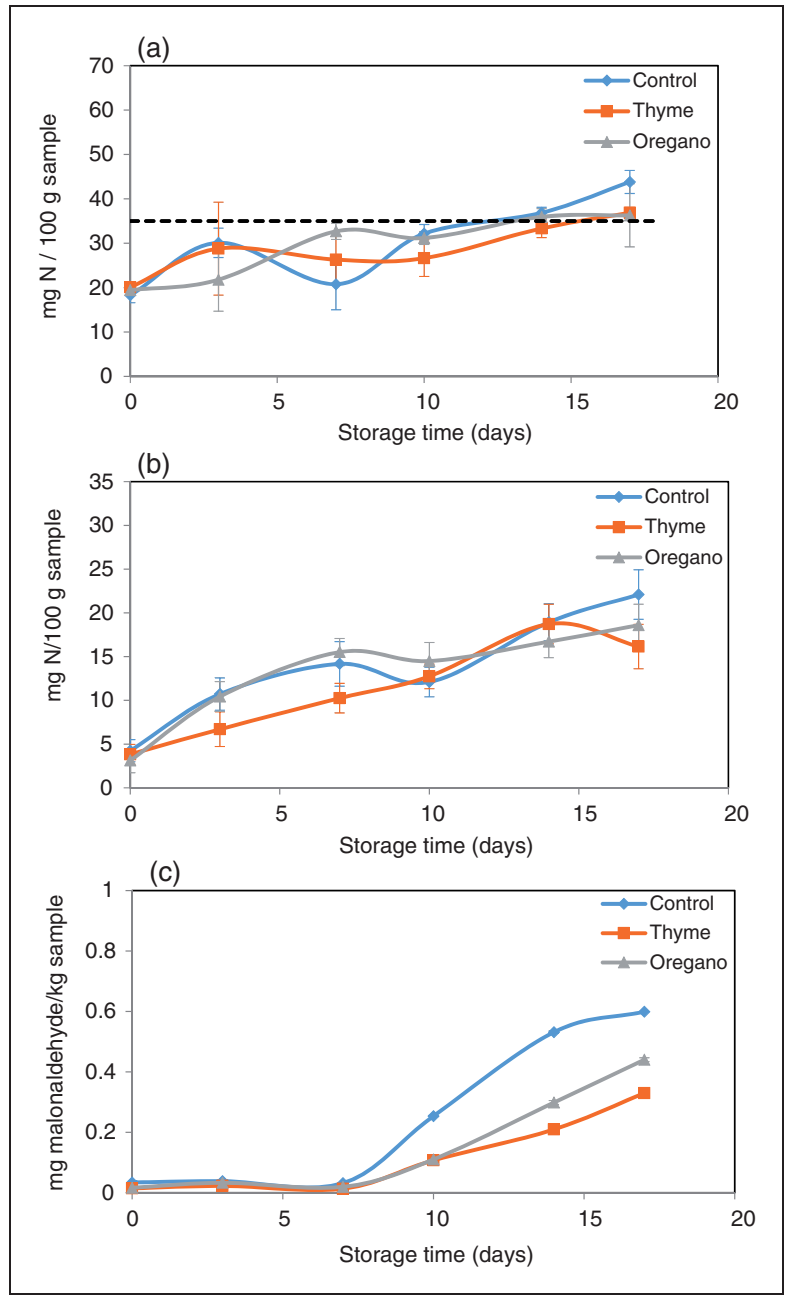

Figure 2. Evolution of TVB-N (a), TMA-N (b) and TBA index (c), in salmon and seaweed burgers: without EOs (control), with thyme EO (thyme) and with oregano EO (oregano), during 17 days of storage at $4{ }^{\circ} \mathrm{C}$. (means and standard deviations). Dashed line shows the acceptability limit.

during the storage time can be observed for all the samples. Samples with EOs showed lower values of this parameter than $\mathrm{Ct}$ samples, as occurred with TVB-N. Og samples exhibited a similar pattern to the control 
samples, except for the last day of analysis, where the values were lower in burgers with oregano EO. T burgers had a slower evolution during the first days of storage. However, from day 10 these samples reached similar values to $\mathrm{Ct}$ and $\mathrm{Og}$ burgers.

Regarding the TBA index, the initial values were low for the three types of burgers, remaining stable until day 7 of analysis. From this day onwards, a gradual increase was observed in all samples. The Ct samples exhibited a significantly higher increase than those with thyme and oregano EOs. This fact shows the antioxidant effect of the EOs, which agrees with other studies on thyme and oregano (Kostaki et al., 2009; Kykkidou et al., 2009; Mexis et al., 2009). Marino et al. (1999) reported the important antioxidant potential of thyme extract due to the high concentrations of phenolic compounds, including carvacrol, thymol, p-cymene, among others. Different acceptability limits have been given for this parameter in different fish species. No absolute limit for TBA index has been established for fish or fish products in general. According to Conell (1995), the limit would be $1-2 \mathrm{mg}$ MDA $/ \mathrm{kg}$; whereas other authors have given higher values. Although $\mathrm{Ct}$ samples showed TBA values significantly higher than those of burgers with EOs, it is important to note that the value reached by control samples at the end of storage was $0.599 \mathrm{mg}$ MDA $/ \mathrm{kg}$. Taking into account the lowest acceptability limits for this parameter (around $1 \mathrm{mg} \mathrm{MDA} / \mathrm{kg}$ ), that value is considered to be low. It can be concluded that any of the burgers evaluated exhibited an important oxidation degree. This demonstrates that, in addition to the antioxidant effect of the EOs, the vacuum packaging would play a decisive role in burger preservation against oxidation. It is also important to mention that in numerous studies, the antioxidant capacity of seaweeds has been proven (Farvin and Jacobsen 2013; López-López et al., 2009).

The textural parameters are shown in Table 2. The initial values of hardness were similar in the three burgers. For the three types of samples, a fluctuation of this parameter could be observed throughout the storage, without a clear trend. Therefore, the EOs incorporation had no effect on this textural parameter. This behaviour could be due to the fact that the preparation of the burgers included mincing the fish; consequently, the muscle structure was destroyed from day 0 . Adhesiveness values also varied throughout the time period with no trend. Elasticity and chewiness values remained constant until day 14 of storage, slightly increasing at the end of the study. Cohesiveness and resilience remained stable during all the time. These results indicate that the EOs did not affect the evaluated texture parameters or their evolution through the storage time. In work carried out on red drum fillets with different types of EOs, a positive effect was observed on the evolution of fish hardness (Cai et al., 2015). In this work, since the fish was previously minced, the texture evolution has not reflected the spoilage of the product and, therefore, although the EOs would have had a preservative action, this could not be reflected on the texture study.

\section{Changes in the microbial parameters during} storage. Evolution of mesophilic and Enterobacteriaceae counts in the three types of burgers $(\mathrm{Ct}, \mathrm{T}$ and $\mathrm{Og}$ ) during cold storage is shown in Figure 3(a) and (b), respectively. Levels of mesophilic counts of $7 \log \mathrm{cfu} / \mathrm{g}$ have been established as the acceptability limit, based on the criteria established by the International Commission on Microbiological Specifications for Foods (1986) and numerous studies of fish shelf life (Cai et al., 2015; Kykkidou et al., 2009; Özyurt et al., 2012). At the beginning of the study, the mesophilic counts in the three types of samples were around $5 \log \mathrm{cfu} / \mathrm{g}$. A progressive increase of the growth of this microorganism was observed until day 10 for all samples, with no significant differences between them. However, from day $10, \mathrm{Ct}$ and $\mathrm{Og}$ burgers exhibited a faster increase compared with $\mathrm{T}$

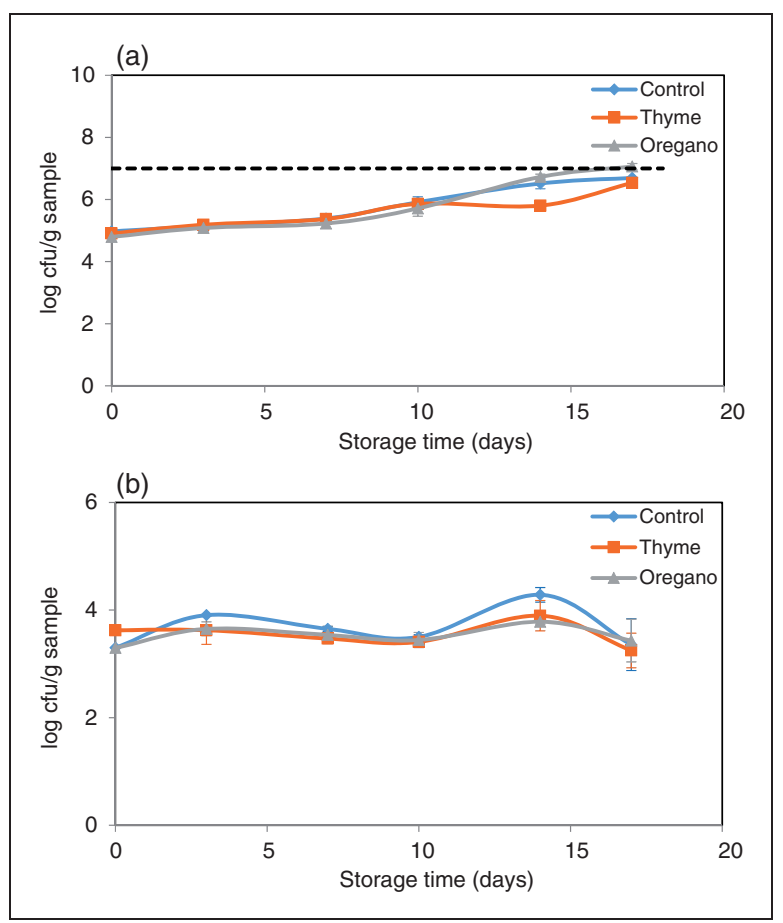

Figure 3. Evolution of mesophilic bacteria (a) and Enterobacteriaceae (b) in salmon and seaweed burgers: without EOs (control), with thyme EO (thyme) and with oregano EO (oregano), during 17 days of storage at $4{ }^{\circ} \mathrm{C}$ (means and standard deviations). Dashed line shows the acceptability limit. 
samples. At the end of the study, all samples reached levels near the acceptability limit $\left(10^{7} \mathrm{cfu} / \mathrm{g}\right)$.

The oregano EO, therefore, at the concentration used in this study, did not exert any inhibitory effect on mesophilic growth. Although the thyme EO slows down the microbial growth, there was no noticeable improvement of the T burger's shelf life. In order to delay microbial spoilage, a higher concentration of both EOs would be necessary. However, the increase of the EOs concentration would affect the sensory quality.

Based on the results of mesophilic growth, the shelf life of the burgers (Ct, Og or T) would be lower than or equal to 17 days.

Regarding the Enterobacteriaceae, fluctuations of counts were observed during storage with no clear trend. Although $\mathrm{C}$ samples showed slightly higher counts on some sampling days, at the end of the study, Enterobacteriaceae levels were similar in the three types of burgers, which demonstrated that thyme and oregano EOs did not have antimicrobial effect under the conditions used in this study.

In work carried out on trout fillets using oregano EO at $0.4 \%(\mathrm{v} / \mathrm{w})$, an important reduction in the mesophilic and Enterobacteriaceae counts was observed, extending the shelf life by 3-4 days (Mexis et al., 2009). Similar results were obtained in a study conducted on swordfish with thyme $(0.1 \%)$, with a shelf life extension of about three days.

The results of the present study demonstrated that the oregano or thyme EOs added to salmon and seaweed burgers at $0.05 \%(\mathrm{v} / \mathrm{w})$ achieved a reduction in the degree of sample oxidation, but they did not slow down microbial growth to the necessary levels to extend the burger's shelf life.

Given that product shelf life was limited by the TVB$\mathrm{N}$ contents and mesophilic growth, both EOs should be incorporated at higher concentrations to be effective in the improvement of hygienic quality of burger made from salmon and seaweed. Taking into account that, from a sensorial point of view, this increase would not be possible, combinations of the different EOs and/or combinations with other preservation methods would be interesting, since several authors have demonstrated that they can have a synergetic effect on food preservation (Calo et al., 2015; Cherrat et al., 2014; De Oliveira et al., 2015). In this way, low concentrations of EOs could be used to achieve microbial inhibition without compromising burger sensory quality.

\section{Multifactor ANOVA}

An ANOVA multifactor was conducted to study the influence of the EOs and the storage time, on the parameters analysed in the burgers. Table 3 shows the
Table 3. F-ratio values and significance levels obtained in the multifactor ANOVA for the physicochemical and microbiological parameters according to factors: type of sample $(\mathrm{S})$, storage time $(\mathrm{t})$ and their interaction $(\mathrm{S} \times \mathrm{t})$

\begin{tabular}{|c|c|c|c|}
\hline & $S$ & $\mathrm{~T}$ & $\mathrm{~S} \times \mathrm{t}$ \\
\hline $\mathrm{pH}$ & $1.87^{\mathrm{ns}}$ & $62.57^{* \star \star}$ & $2.42^{\text {ns }}$ \\
\hline Moisture & $6.63^{* *}$ & $19.73^{\star \star \star}$ & $0.79^{\text {ns }}$ \\
\hline TVB-N & $0.32^{\mathrm{ns}}$ & $15.78^{\star \star \star}$ & $1.64^{\mathrm{ns}}$ \\
\hline TMA-N & $4.50 *$ & $50.03^{\star \star \star}$ & $1.67^{\mathrm{ns}}$ \\
\hline TBA index & $1535.78^{\star \star \star}$ & $5871.80 * \star \star$ & $283.60 * * *$ \\
\hline \multicolumn{4}{|l|}{ Texture } \\
\hline Hardness & $0.23^{\mathrm{ns}}$ & $2.98 *$ & $1.47^{\mathrm{ns}}$ \\
\hline Adhesiveness & $0.89^{\text {ns }}$ & $3.79 *$ & $1.68^{\mathrm{ns}}$ \\
\hline Elasticity & $0.46^{\mathrm{ns}}$ & $24.09 * * *$ & $0.23^{\text {ns }}$ \\
\hline Cohesiveness & $0.27^{\mathrm{ns}}$ & $3.45^{\star}$ & $0.58^{\mathrm{ns}}$ \\
\hline Chewiness & $0.02^{\text {ns }}$ & $7.21 * * \star$ & $0.65^{\mathrm{ns}}$ \\
\hline Resilience & $0.81^{\mathrm{ns}}$ & $1.05^{\mathrm{ns}}$ & $1.00^{\mathrm{ns}}$ \\
\hline Mesophilic bacteria & $14.95^{\star \star *}$ & $470.79 * * *$ & $16.78 * * \star$ \\
\hline Enterobacteriaceae & $3.34^{\star}$ & $16.48^{\star \star \star}$ & $2.13^{\star}$ \\
\hline
\end{tabular}

ns: non-significant; TBA: thiobarbituric acid; TMA-N: trimethylamine nitrogen; TVB-N: total volatile basic nitrogen.

${ }^{\star} \mathrm{p}<0.05 ;{ }^{* \star} \mathrm{p}<0.01 ;{ }^{* *} \mathrm{p}<0.001$.

F-ratio and the significance level of factors and their interactions. The F-ratio represents the quotient between variability due to the effect considered and the residual variance. A higher value of F-ratio means a more marked effect of that factor (type of sample or storage time) on a variable (parameters analysed).

The statistical analysis showed that the use of thyme or oregano EOs significantly affected the TBA index and mesophilic counts. Storage time had a significant effect in practically all the analysed variables, although, as has been mentioned before, some parameters varied throughout the storage time with no clear trend. Regarding interaction between the factors, it is important to highlight that it was significant for the TBA index and mesophilic counts, which demonstrated that the evolution of both parameters was different depending on the type of sample.

\section{CONCLUSIONS}

Cinnamon EO confers an intense odour and flavour, even at low concentrations $(0.025 \mathrm{v} / \mathrm{w})$, which make it unsuitable for use as a natural preservative in salmon and seaweed burgers. Red thyme and oregano EOs could be incorporated to these burgers at concentrations of $0.05 \%(\mathrm{v} / \mathrm{w})$ conferring a typical odour and flavour, but which may be sensorially acceptable.

Oregano EO at $0.05 \%(\mathrm{v} / \mathrm{w})$ in the burgers does not affect the changes of TVB-N or TMA-N during cold storage. The red thyme EO at the same concentration 
slows down the increase of both parameters; nevertheless, this decrease in the TVB-N content is not enough to significantly extend burger's shelf life.

Moisture content, $\mathrm{pH}$ and texture of the product are not affected by the red thyme or oregano EOs. Both EOs have a marked influence on the inhibition of burger oxidation. The antioxidant capacity of seaweed together with the vacuum packaging, also protect burgers against oxidation, meaning that oxidation is not a spoilage process in this product.

Enterobacteriaceae growth is not affected by the presence of both EOs at the concentrations studied, while the addition of red thyme EO causes a decrease in mesophilic growth. However, this inhibition is not enough to increase burger's shelf life.

In order to extend the product shelf life, both EOs had to be used at higher concentrations, but this is not possible from a sensorial point of view. The combination of the different EOs and/or combinations with other preservation techniques would be interesting, since they may have a synergetic effect on burger preservation. In this way, low concentrations of EOs could be used to achieve microbial inhibition without compromising the burger sensory quality.

\section{DECLARATION OF CONFLICTING INTERESTS}

The author(s) declared no potential conflicts of interest with respect to the research, authorship, and/or publication of this article.

\section{FUNDING}

The author(s) disclosed receipt of the following financial support for the research, authorship, and/or publication of this article: The experiment reported here is a part of a project financially supported by Universitat Politècnica de València ('SaPesAl' (UPV-FE-2014-55)), which the authors gratefully acknowledge. The translation of this paper was funded by the Universitat Politècnica de València, Spain.

\section{ORCID ID}

D Dolea (D) http://orcid.org/0000-0001-8278-7967

\section{REFERENCES}

Abdollahzadeh E, Rezaei M and Hosseini H. (2014). Antibacterial activity of plant essential oils and extracts: The role of thyme essential oil, nisin, and their combination to control Listeria monocytogenes inoculated in minced fish meat. Food Control 35: 177-183.

Association of Official Analytical Chemists (AOAC). (1997). Official Methods of Analysis, 16th ed. Washington, DC: Association of Official Analytical Chemists.

Ballester-Costa C, Sendra E, Fernández-López J, PérezÁlvarez JA and Viuda-Martos M. (2013). Chemical composition and in vitro antibacterial properties of essential oils of four Thymus species from organic growth. Industrial Crops and Products 50: 304-311.
Bourne MC. (1978). Texture profile analysis. Food Technology 32: 62-66, 72.

Cai L, Cao A, Li Y, Song Z, Leng L and Li J. (2015). The effects of essential oil treatment on the biogenic amines inhibition and quality preservation of red drum (Sciaenops ocellatus) fillets. Food Control 56: 1-8.

Calo JR, Grandall PG, O'Bryan CA and Ricke SC. (2015). Essential oils as antimicrobials in food systems: A review. Food Control 54: 111-119.

Cherrat L, Espina L, Bakkali M, García-Gonzalo D, Pagan R and Laglaoui A. (2014). Chemical composition and antioxidant properties of Laurus nobilis L. and Myrtus communis L. essential oils from Morocco and evaluation of their antimicrobial activity acting alone or in combined processes for food preservation. Journal of the Science of Food and Agriculture 94: 1197-1204.

Cofrades S, López-López I, Solas MT, Bravo L and Jiménez-Colmenero F. (2008). Influence of different types and proportions of added edible seaweeds on characteristics of low-salt gel/emulsion meat systems. Meat Science 79: 767-776.

Conell JJ. (1995). Control of Fish Quality, 4th ed. London: Fishing News Books Limited.

De Oliveira TLC, De Castro-Leite Junior BR, Ramos ALS, Mendes-Ramos E, Hilsdorf-Piccoli R and Cristianini M. (2015). Phenolic carvacrol as a natural additive to improve the preservative effects of high pressure processing of lowsodium sliced vacuum-packed turkey breast ham. $L W T-$ Food Science and Technology 64: 1297-1308.

European Commission. (2005). Commission regulation 2074/ 2005 of 5 December 2005, implementing measures for certain products under regulation (...). Section II, Chapter I: Total Volatile Basic Nitrogen (TVB-N) Limit Values for Certain Categories of Fishery Products and Analysis Methods To Be Used. Official Journal of the European Union, L338: 1.

Farvin SKH and Jacobsen C. (2013). Phenolic compounds and antioxidant activities of selected species of seaweeds from Danish coast. Food Chemistry 138: 1670-1681.

Gómez-Ordóñez E, Jiménez-Escrig A and Rupérez P. (2010). Dietary fibre and physicochemical properties of several edible seaweeds from the northwestern Spanish coast. Food Research International 43: 2289-2294.

Gupta S and Abu-Ghannam N. (2011). Recent developments in the application of seaweeds or seaweed extracts as a means for enhancing the safety and quality attributes of foods. Innovative Food Science and Emerging Technologies 12: 600-609.

ICMSF. (1986). Sampling plans for fish and shellfish. In: ICMSF (ed.) Microorganisms in Foods. Sampling for Microbiological Analysis: Principles and Scientific Applications. 2nd ed, Vol. 2. Toronto: University of Toronto Press, pp.181-196.

ISO 4833 (ed.). (2003). Microbiology of Food and Animal Feeding Stuffs. Horizontal Method for the Enumeration of Microorganisms. Colony-Count Technique at $30^{\circ} \mathrm{C}$. Geneva: International Organization for Standardization.

ISO 21528-2 (ed.). (2004) Microbiology of Food and Animal Feeding Stuffs - Horizontal Methods for the Detection and Enumeration of Enterobacteriaceae - Part 2: Colony-Count 
Method. Geneva: International Organization for Standardization.

Kostaki M, Giatrakou V, Savvaidis IN and Kontominas MG. (2009). Combined effect of MAP and thyme essential oil on the microbiological, chemical and sensory attributes of organically aquaculture sea bass (Dicentrarchus labrax) fillets. Food Microbiology 26: 475-482.

Kykkidou S, Giatrakou V, Papavergou A, Kontominas MG and Savvaidis IN. (2009). Effect of thyme essential oil and packaging treatments on fresh Mediterranean swordfish fillets storage at $4{ }^{\circ} \mathrm{C}$. Food Chemistry 115: 169-175.

López-López I, Bastida S, Ruiz-Capillas C, Bravo L, Larrea MT, Sánchez-Muniz F, et al. (2009). Composition and antioxidant capacity of low-salt meat emulsion model systems containing edible seaweeds. Meat Science 83(3): 492-498.

Malle P and Tao SH. (1987). Rapid quantitative determination of trimethylamine using steam distillation. Journal of Food Protection 50: 756-760.

Marino M, Bersani C and Comi G. (1999). Antimicrobial activity of the essential oils of Thymus vulgaris L measured using a bioimpedometric method. Journal of Food Protection 62: 1017-1023.

Mexis SF, Chouliara E and Kontominas MG. (2009). Combined effect of an oxygen absorber and oregano essential oil on shelf life extension of rainbow trout fillets stored at $4{ }^{\circ}$ C. Food Microbiology 26: 598-605.

Özyurt G, Kuley E, Balikçi E, Kaçar Ç, Gökdogan S, Etyemez M, et al. (2012). Effect of the icing with rosemary extract on the oxidative stability and biogenic amine formation in sardine (Sardinella aurita) during chilled storage. Food and Bioprocess Technology 5: 2777-2786.
Özyurt G, Kuley E, Özkütük S and Özogul F. (2009). Sensory, microbiological and chemical assessment of the freshness of red mullet (Mullus barbatus) and goldband goatfish (Upeneus moluccensis) during storage in ice. Food Chemistry 114: 505-510.

Peinado I, Girón J, Koutsidis G and Ames JM. (2014). Chemical composition, antioxidant activity and sensory evaluation of five different species of brown edible seaweeds. Food Research International 66: 36-44.

Perricone M, Arace E, Corbo MR, Sinigaglia M and Bevilacqua A. (2015). Bioactivity of essential oils: A review on their interaction with food components. Frontiers in Microbiology 6: 76.

Pesavento G, Calonico C, Bilia AR, Barnabei M, Calesini F, Addona R, et al. (2015). Antibacterial activity of Oregano, Rosmarinus and Thymus essential oils against Staphylococcus aureus and Listeria monocytogenes in beef meatballs. Food Control 54: 188-199.

Rupérez P. (2002). Mineral content of edible marine seaweeds. Food Chemistry 79: 23-26.

Sanjuás-Rei M, Pourashouri $\mathrm{P}$, Barros-Velázquez $\mathrm{J}$ and Aubourg SP. (2012). Effect of oregano and thyme essential oils on the microbiological and chemical quality of refrigerated $\left(4{ }^{\circ} \mathrm{C}\right)$ ready-to-eat squid rings. International Journal of Food Science and Technology 47: 1439-1447.

Tarladgis BG, Watts BM, Younathan MT and Dugan LR Jr. (1960). A distillation method for the quantitative determination of malonaldehyde in rancid foods. Journal of American Oil Chemists Society 37: 44-48. 